\title{
EVIDÊNCIAS EXPERIMENTAIS DA CORRELAÇÃO ENTRE LIGADURA DE DUCTO BILIAR E ENDOTOXEMIA EM RATOS WISTAR
}

G.A. ANTONIK; T.J. EID; V.R.C.D. FONSECA; R.R. GAMA; A. HARTMANN; H.P.V. MARQUES;

M.B. OBAYASHI; A.S.C. TEIXEIRA; K. CHI

Hospital Universitário Evangélico de Curitiba e Faculdade Evangélica de Medicina do Paraná

Introdução e Objetivos: Apesar do efeito mais conhecido da bile relacionar-se à emulsificação e absorção de gorduras, ela exerce também função no controle da microflora bacteriana intestinal. Sendo assim, este estudo objetivou avaliar a obstrução biliar e métodos terapêuticos úteis no controle da endotoxemia e da liberação da citocina próinflamatória, o TNFa, em modelo experimental de oclusão biliar extra-hepática em ratos. Método: Ultilizaram-se ratos Wistar ( $n=34)$, separados em: grupo não operado - controle $(N)$, grupo obstrução-simulada (S), grupo obstrução biliar sem tratamento (C) , grupo obstrução biliar e tratamento com lactulose na dose de $1,3 \mathrm{mg} / \mathrm{dia}(\mathrm{L})$ e grupo obstrução biliar e tratamento com sais biliares da dose de $4 \mathrm{~g} / \mathrm{dia}$. A eficácia dos tratamentos foi avaliada comparando-se as médias obtidas da contagem de colônias bacterianas aeróbias (AER) e anaeróbicas (ANER) cecais, dosagem de endotoxina e TNFa. A obstrução biliar foi comprovada pela dosagem de bilirrubinas totais. Resultados: grupo S: endotoxina $0,27 \pm 0,028 \mathrm{EU} / \mathrm{ml}$, TNFa $1,298 \pm 245,72 \mathrm{pg} / \mathrm{ml}$, bilirrubina $1,921 \pm 0,332 \mathrm{mg} / \mathrm{dl}$, AER $82,2 \pm 13,94 X 10^{-6}$ UFC/ml, ANAER 62,6 $\pm 23,14 \times 10^{-3} \mathrm{UFC} / \mathrm{ml}$. Grupo L: endotoxina $0,1134 \pm \mathrm{o}, 059 \mathrm{EU} / \mathrm{ml}, \mathrm{TNFa} 1,308 \mathrm{~V} 289,51 \mathrm{pg} / \mathrm{ml}$, bilirrubinas 2,035 $\pm 0,263 \mathrm{mg} / \mathrm{dl}$, AER $56,2 \pm 17,1 \times 10^{-6} \mathrm{UFC} / \mathrm{ml}$, ANAER 46,5 $\pm 19,346 \times 10^{-3}$ UFC/ml. Grupo SB: endotoxina $0,188 \pm 0,023 \mathrm{EU} / \mathrm{ml}$, TNFa $1,054 \pm 141,62 \mathrm{pg} / \mathrm{ml}$, bilirrubina $1,948 \pm 0,221 \mathrm{mg} / \mathrm{dl}$, bactérias aeróbicas $87,55 \pm 22,63 \times 10^{-6} \mathrm{UFC} / \mathrm{ml}$, bactérias anaeróbicas $44,66 \pm 13,40 \times 10^{-3} \mathrm{UFC} / \mathrm{ml}$. Conclusão: O procedimento de obstrução biliar induziu endotoxemia, liberação de TNFa e promoveu aumento da colonização bacteriana cecal. O tratamento com lactulose foi mais efetivo que a reposição de sais biliares, mostrando significante diminuição da microflora aeróbica cecal e melhor controle da endotoxemia. Não houve diferenças significantes das variáveis estudadas no grupo de reposição de sais biliares quando comparado ao grupo de obstrução simulada. 